\title{
EXAMINING THE PROBABLE THREE THESIS OF THE GLOBALIZATION EFFECT ON CULTURE BY MEANS OF THE CONSUMER'S ETHNOCENTRIC TENDENCY LEVEL ${ }^{1}$
}

\author{
DOI: 10.17261/Pressacademia.2017.716 \\ RJBM-V.4-ISS.3-2017(15)-p.390-399
}

\section{Husniye Ors ${ }^{1}$, Ozlem Catli ${ }^{2}$, Aysegul Ermec Sertoglu ${ }^{3}$,}

${ }^{1}$ Gazi Üniversitesi, iktisadi ve İdari Bilimler Fakültesi, Uluslararası Ticaret Bölümü, Beşevler, Ankara, Türkiye. husniye@gazi.edu.tr

${ }^{2}$ Gazi Üniversitesi, iktisadi ve İdari Bilimler Fakültesi, Uluslararası Ticaret Bölümü, Beşevler, Ankara, Türkiye. ozlembare@gazi.edu.tr

${ }^{3}$ Gazi Üniversitesi, iktisadi ve İdari Bilimler Fakültesi, Uluslararası Ticaret Bölümü, Beşevler, Ankara, Türkiye. aermec@gazi.edu.tr

To cite this document

Ors, H., O. Catli and A.E.Sertoglu, (2017) Examining the probable three thesis of the globalization effect on culture by means of the consumer's ethnocentric tendency level. Research Journal of Business and Management (RJBM), V.4, Iss.3, p. 390-399.

Permemant link to this document: http://doi.org/10.17261/Pressacademia.2017.716

Copyright: Published by PressAcademia and limited licenced re-use rights only.

\section{ABSTRACT}

Purpose- By the fact that globalization is an influencing factor shaping all structures of society, the aim is to analyze three thesis about the cultural efffects of globalization by consumer ethnocentrism; additionally to examine the consumer ethnocentirsm by demographic factors. Methodology-: As a descriptive research, the study has been done by face-to-face survey method and convenience sampling conducted on 331 respondents.

Findings- In order to measure the ethnocentric levels of consumers, 17-unit CETSCALE scale was used, and the measurement was found to be reliable. According to the analysis, it has been found that the ethnocentric level of Turkish consumers is medium, does not change according to age, but changes according to gender. Also, ethnocentric level of Turkish consumers is lower for those who has higher education level.

Conclusion- According to the study, 'hybridization' thesis is found acceptable among three probable thesis of the globalization effect on culture.

Keywords: Globalization, culture, ethnocentrism, consumer behavior, marketing

JEL Codes: M30, M31, Z10

\section{TÜKETiCiNIN ETNOSENTRIK EĞiLiM DÜZEYi ARACILIĞIYLA KÜRESELLEŞMENIN KÜLTÜRE ETKISINE ILIŞKIN OLASI ÜÇ TEZIN SINANMASI}

\section{ÖZET}

Amaç - Küreselleşmenin toplumun tüm yapılarını şekillendiren bir etki faktörü olması gerçeği ile kültürel etkilerine ilişkin tanımlanan üç tezin tüketici etnosentrizmi ile sınanması, ayrıca tüketici etnosentrizminin demografik faktörler itibariyle incelenmesidir.

Yöntem - Tanımlayııı bir nitelik taşıyan araştırma, yüz yüze anket yöntemi ve kolayda örnekleme ile 331 cevaplayıcı üzerinde yapılmıştır. Bulgular- Tüketicilerin etnosentrik düzeylerini ölçmek için 17-birimlik CETSCALE ölçeği kullanılmış olup, ölçüm güvenilir bulunmuştur. Yapılan analizler sonucunda Türk tüketicilerin etnosentrik eğilim düzeylerinin orta düzeyde olduğu, yaşa göre değişmediği, cinsiyete göre ise değiştiği, eğitim düzeyi yüksek olanların daha düşük düzeyde etnosentrik eğilim gösterdiği ortaya konmuştur.

Sonuç- Araştırma ile küreselleşmenin kültürel etkilerine iliş̧in olası tezlerden 'hibritleşme' tezinin kabul edilebilir olduğu elde edilmiştir.

Anahtar Kelimeler: Küreselleşme, kültür, tüketici etnosentrizmi, tüketici davranışları, pazarlama JEL Kodları: M30, M31, Z10

\footnotetext{
${ }^{1}$ This article is expanded version of the paper presented at the Global Business Research Congress 2017.
} 


\section{GíRiş}

Küreselleşme sosyal bilimler alanında son yıllarda çok yoğun olarak araştırılan konular arasında yer almış ve yer almaya devam etmektedir. Küreselleşmenin kültüre olan etkilerini inceleyen yazında, diğer tezlerin yanı sıra küreselleşmenin kültürü homojenleştirdiği tezi daha yüksek düzeyde destek görmektedir. Bu yaklaşıma göre diğer ülkelere transfer edilen Batı kültürü, gittiği ülkenin milli kültürünün tüm öğelerine yayılım göstermekte ve bu yayılım ülke vatandaşlarının tüketim tercihlerine de yansımaktadır. Bu yaklaşım temel alındığında, tüketicinin satın alma davranışında 'yerli ürün tercihi'nin seçim kriterleri arasında yer almaması beklenir. Tüketicinin bu yöndeki davranışının pazarlama literatüründe 'tüketici etnosentrizmi' şeklinde kavramsallaştırılan davranışın karşı kutbunda yer aldığı söylenebilir.

Tüketici etnosentrizmi; tüketicilerin yerli ürünler dışındaki ürünleri kullanmanın ve satın almanın uygunluğunu ve ahlaki olup olmamasını sorgular; yerli ürün alınmasını destekler ve bu ürünlere yabancı menşeli ürünlerden daha fazla değer atfeder. Bu tüketicilerin en belirgin özellikleri; yabancı ürün satın almanın yanlış olduğuna, bu durumun ülke ekonomisine zarar verdiğine ve işsizliğe açtığına olan inançlarıdır. Bu tüketim davranışı yaklaşımının küreselleşen kültürün içinde hayatiyet bulmasının oldukça zor olduğu söylenebilir. Mevcut çalışmada iki önemli kavram olan küreselleşmenin kültüre etkisi ve tüketici etnosentrizmi irdelenerek, bu etkinin tüketici davranışı aracılığıyla gerçek durumuna açıklık getirilmeye çalışılmıştır.

\section{LITERATÜR INCELEMESI}

\subsection{Küreselleşme ve Kültürel Etkileri}

Küreselleşme, özellikle teknolojik gelişmelerle beraber bilginin, insanın, sermayenin, fikirlerin sınır tanımadan serbestçe dolaşır hale gelmesine zemin hazırlamış, ticarette "coğrafik alan"a olan ihtiyacı ortadan kaldırarak tüketicilerin bir 'dünya tüketicisi' olması sonucunu doğurmuştur (Harvey, 1992; McNeill, 1986). Yaşadığımız dönemde küreselleşmede gelinen son durum; dünyanın çeşitli parçaları arasında karşılıklı-bağımlıık ve yeni şekilde bütünleşmede; 'zaman-mekan sıkışması' olarak kavramlaştırılmış ve böylece 'zamanın mekandan bağımsızlaşması', küreselleşmenin ön koşulu (Giddens, 1998: 66) haline gelmiştir.

21. yüzyılda, özellikle iletişim teknolojilerindeki gelişmeler sayesinde bir "küresel kültür"ün doğduğu varsayımları sosyal bilimlerde yaygın kabul haline gelmiş olup, küreselleşmenin kültürel etkileri üzerine tezler geliştirilmiş ve geliştirilmeye devam edilmektedir. Konu ile ilgili günümüz literatüründe üç-olası tez tanımlanmıştır. Bunlar; homojenleşme tezi, kutuplaşma tezi ve hibritleşme tezidir (Holton, 2013: 63). Bu tezler aşağıdaki gibi özetlenebilir:

- Homojenleşme Tezi: Bu teze göre küreselleşme; kültürel özellikler ile pratik uygulamaları birbirine yaklaştırmış ve kültürü homojenleştirmiştir (Giddens, 1998: 66). Kültürün homojenleşmesi; 'Amerikanlaşma' anlamına gelmekte, küresel tüketim yalnızca ürünlerin bir ihtiyaca cevap vermesine bağlı olmamakta aynı zamanda Hollywood endüstrisi ile zenginlik rüyaları, kişisel başarı ve hedonizm-temelli ürünlerin de sunulması ile Amerikan ve Batı kültürü diğer ülkelere transfer edilmektedir.

-Kutuplaşma Tezi: Bu tezin savunucularının temel aldığı dayanak; medeniyetler çatışmasıdır. Buna göre küreselleşme ile etnik temizlik, ulusalcılık ve nefrete dayalı politik kimlikler meydana gelmiş ve bu medeniyetler zıt-iki kutupta (Keyman, 1998) kümelenmiştir; batının Orta Doğu İslam coğrafyasını statik, otoriter, 'şark' olarak; batıyı ise akılcı, hoşgörülü, yenilikçi ve dinamik olarak gördügü iki kutup olarak.

-Hibritleşme Tezi: Bu tezin savunucularına göre günümüzde kültürler yüksek düzeyde birbirine girmiş ve karışmış olduğundan, saf, otantik bir kültürden bahsetmek mümkün değildir (Hannerz, 1998). Robertson'a ( 1998) göre küreselleşme ile farklı kültürler farklı derecelerde birbirleri ile etkileşime girmekte ve bunun sonucu küresel kültür kendini kısmen ulusal kültür ile ve küresel etkileşimlerin özgünlüğü ile yapılanmaktadır.

\subsection{Tüketici Etnosentrizmi}

Sosyoloji yazınında William G.Summer tarafından kavramlaştırılan etnosentrizm; bireyin, kendisini onun bir üyesi olarak kabul ettiği etnik grubu her şeyin merkezi olarak görmesi, toplumdaki diğer sosyal grupları üyesi olarak algıladığı grup perspektifinden değerlendirmesi, kendi kültürüne benzemeyenleri ret etmesidir (Shimp, Sharma, 1987: 280). Entnosentrizm eğilimli bireylerin üyesi oldukları etnik grubu yaşam alanlarının merkezine koymaları; kendi kültür özellikleri ile gurur duyma ve diğer grupların kültür özelliklerini hor görme (Netemeyer, Durvasula \& Lichtenstein, 1991) sonucunu beraberinde getirmektedir.

Sosyoloji alanında, özellikle kültüre ilişkin çalışmalarda yüksek düzeyde çalışılan bu kavram, diğer sosyal disiplinlerin yanı sıra pazarlama alanında da yaygın olarak araştırılmaktadır. Etnosentrizm kavramı pazarlama yazınına "tüketici Etnosentrizmi" ifadesiyle, 1987 yılında Shimp ve Sharma tarafından kazandırılmıştır. Tüketici etnosentrizmi; pazar bölümlendirme, ürün/marka konumlandırma, mamul/hizmet kalite iyileştirme, sosyal sorumluluk projelerine temel oluşturma gibi birçok yönetsel pazarlama alanlarında kullanılmaktadır. Tüketici etnosentrizmi; pazarlama yöneticilerinin hedef pazarlarındaki tüketicilerin yabancı ve yerli ürünlere ilişkin ön yargı ve ön kabullerini anlayabilmelerini sağlayarak en uygun pazarlama stratejilerini geliştirmelerine katkı (Cateora, 2000) sağlamakta ve pazar bölümlendirme faktörü olarak 
(Kaynak, Kaya, 2002) işlev görmektedir. Tüketici etnosentrizmi; grup içindeki kabullere etki ettiğinden grup üyesi olan bireyin kişiliğine yön verir ki bu etki kendini satın alma davranışında da göstererek kabul edilen veya edilmeyen satın alma davranışının 'hangisi' olduğunun anlaşımasını sağlar (Shimp, Sharma, 1987), grup üyesinin yabancı menşeli ürünleri satın alma ve kullanmanın ne derece etik olup olmadığını gösterir. Yapılan araştırmalar, yerli ürün tercih etme ile pozitif yönde (Balabanis, Diamantopoulis, 2004), yabancı ürün tercih etme ile negatif yönde (Klein, Ettenson \& Morris, 1998) ilişki olduğunu, etnosentrik eğilimi yüksek tüketicilerin düşük olanlara göre kendi ülkesinin ürünlerine daha yüksek değer atfettiklerini, yabancı ürün satın almanın yanlış olduğuna inandıklarını, yabancı ürün satın almanın ülke ekonomisine olumsuz etki ettiği ve işsizliğe yol açtığına inandıklarını, vatanseverlikle ters düştüğü inancını taşıdıklarını, bu nedenle ülke ve milletini seven bireylerin yerli ürün satın almaları gerektiğini düşündüklerini (Balabanis, Diamantopoulos, 2004; Shimp, Sharma, 1987; Shankarmahesh, 2006), yabancı ürün satın almanın kabul edilmeyen bir siyasi davranış olduğunu (Altındaş, Tokol, 2007) ortaya koymuştur.

Tüketici davranışları yazınında etnosentrizm ile ilgili araştırmaların ortaya koyduğu sonuçların dikkat çekici tarafı; gelişmiş ülke vatandaşlarının kendi ülkelerinde üretilen ürünlerin daha iyi olduğuna olan inançlarından dolayı yerli ürünü tercih ettikleri (Klein, Ettenson \&Morris, 1998); bunun aksine gelişmekte olan ülke vatandaşlarının ekonomisi daha gelişmiş ülke menşeli ürünlerin daha iyi olduğuna ve yerel ürünün kalitesinin düşük olduğuna ilişkin yargılarından dolayı yabancı ürün tercih ettikleri (Wang, Chen, 2004) bulgularıdır. Bu araştırma bulgularının tüketicilerin etnosentrik davranışlarında rasyonel kriterleri de dikkate aldıklarını ortaya koyduğunu gösterdiği ifade edilebilir. Dolaysıyla tüketici etnosentrizmi kavramı sosyal bilimlerde stratejik önemini korumakla beraber, ekonomik avantaj yaratması durumuna bağlı olarak davranışa yön verdiği bulgusu ile paradoksal bir kabule sahip olduğu düşünülebilir.

\section{VERI VE YÖNTEM}

\subsection{Araştırmanın Amacı}

Küreselleşmenin toplumların tüm yapılarına olduğu gibi kültürlerine de etki ettiği yaygın kabuldür. Bu görüş kabul edildiğinde, bunun tüketim kültürüne de yansıması beklenilir. Literatür taramasına istinaden, küreselleşmenin kültürel etkilerine ilişkin olarak tanımlanan olası üç tez mevcuttur ve mevcut araştırma ile bu tezler, tüketici etnosentrizmi ile sınanmak istenmiştir. Bu bağlamda araştırmanın amacı; Türk tüketicilerinin etnosentrik düzeylerini belirlemek, demografik faktörler itibariyle incelemek ve elde edilen sonuçların küreselleşmenin kültürel etkileri bağlamında öne sürülen olası üç tezin sınanmasına katkı sağlamaktır. Bu yönü ile araştırma tanımlayıcı bir özellik taşımaktadır.

\subsection{Araştırma Düzeni}

Araştırmada küreselleşmenin kültürel etkilerinden sosyoloji yazınında çalışılan üç tez dikkate alınmıştır. Toplumlardaki kültürel yapı, o toplumda yaşayan bireylerin kültür kodlarını oluşturur ve bu kodlar sosyal ve ekonomik yapılarda davranışlar olarak kendini ifadeler. Araştırmada küreselleşmenin kültürel etkilerini, toplum bireylerinin tüketim davranışlarından etnosentrik eğilimlerini inceleyerek ortaya koymak hedeflenmiş ve araştırma amacı doğrultusunda belirlenen hedeflere ulaştıracak araştırma düzeni Şekil 1'de gösterilmiştir.

\section{Şekil 1: Araştırma Düzeni}

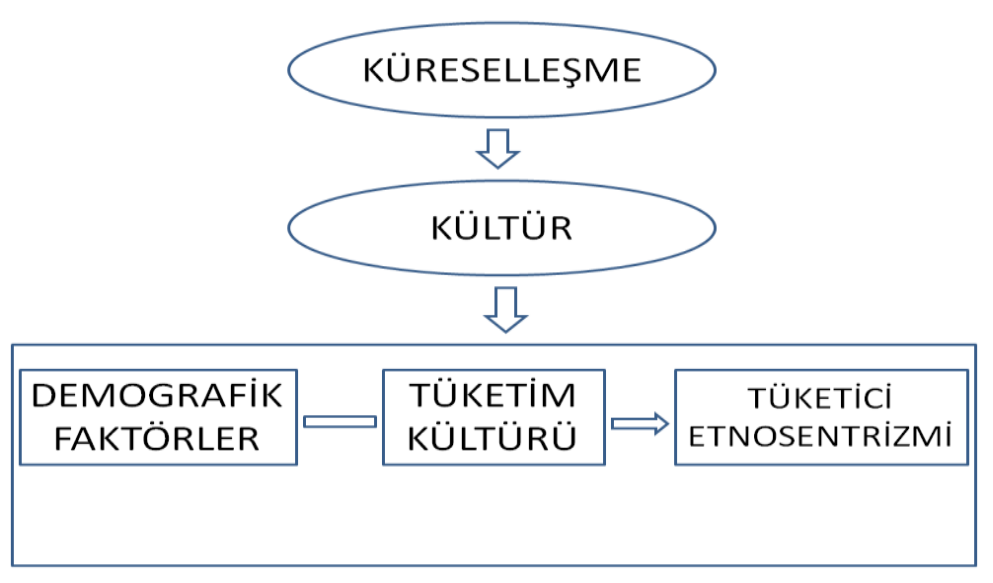

Yukarıda açıklanan kavramsal çerçeve ve bilimsel yazına istinaden, test edilecek tezler aşağıda belirtilmiştir. 
Tez 1: Homojenlik tezine göre küreselleşme kültür homojenliği yaratmış ve tüm kültürleri 'Batı́lılaşma/Amerakınlılaşma' şeklinde etkilemiştir. Bu tez doğru kabul edilirse, Türk tüketicilerinin etnosentrik eğilim düzeylerinin 'düşük' çıkması beklenir. Bu teze ilişkin sınama, aşağıda gösterildiği şekilde formüle edilmiştir.

\section{Homojenlik Tezi Doğru $\quad \Longrightarrow \quad$ Türk Tüketicisinin Etnosentrik Düzeyi Düşük}

Tez 2: Kutuplaşma tezine göre küreselleşme kültür kutuplaşması yaratmış ve tüm toplumlar 'Islam/Doğu Kültürü' ile 'Batı/Amerikan Kültürü' şeklinde iki kupta ayrılmıştır. Bu teze göre Türk tüketicilerinin 'Doğu Kültürü' kategorisinde olması gerekir. Bu tez kabul edilirse, Türk tüketicilerinin etnosentrik eğilim düzeylerinin 'yüksek' çıkması beklenir. Bu teze ilişkin sınama, aşă̆ıda gösterildiği şekilde formüle edilmiştir.

\section{Kutuplaşma Tezi Doğru $\quad \Longrightarrow$ Türk Tüketicisinin Etnosentrik Düzeyi Yüksek}

Tez 3: Hibritleşme tezine göre saf bir kültürden bahsedilemez ve küreselleşme ile farklı kültürler farklı düzeylerde birbirlerini etkilemektedirler. Türk tüketicilerinin etnosentrik eğilim düzeylerinin 'orta' çıkması beklenir. Bu teze ilişkin sınama, aşağıda gösterildiği şekilde formüle edilmiştir.

\section{Hibritleşme Tezi Doğru $\quad \Longrightarrow \quad$ Türk Tüketicisinin Etnosentrik Düzeyi Orta}

Araştırma amacında belirtildiği üzere, Türk tüketicilerin etnosentrik eğilim düzeylerinin demografik faktörler itibariyle ortaya koyabilmek için aşağıdaki hipotezler oluşturulmuştur:

$\mathrm{H}_{1}$ : Tüketicilerin etnosentrik düzeyleri, cinsiyete göre farklılık gösterir

$\mathrm{H}_{2}$ : Tüketicilerin etnosentrik düzeyleri, yaşa göre farklılık gösterir.

$\mathrm{H}_{3}$ : Tüketicilerin etnosentrik düzeyleri, eğitime göre farklıık gösterir.

\section{3. Örneklem}

Araştırmada küreselleşmenin kültürel etkilerine ilişkin sosyoloji yazınında ortaya konan üç tezin tüketim kültürü üzerinden tüketici etnosentrizmi ile sınanması amaçlanmış olduğundan, araştırma birimi Türk tüketicileri olarak tanımlanmıştır. Ana kütlenin çok geniş olması dolayısıyla örnekleme yapılmıştır. Bunun için Ankara ili merkez ilçesinde kolayda örnekleme yöntemine karar verilmiştir.

\subsection{Veri Toplama ve Ölçme Araçları}

Araştırmada veriler anket yöntemi ile toplanmıştır. Bunun için Sosyal Bilimler Enstitüsü Yüksek Lisans öğrencilerinden araştırma metodolojisi eğitimi ve anket uygulaması deneyimine sahip 8 öğrenciye, araştırmacılar tarafından araştırma ve anket ile ilgili detaylı açıklama yapılmıştır. Anket uygulaması tüketim ehliyeti dikkate alınarak 15 yaş üstünde olanlar üzerinde, Ankara ili merkez ilçesinde yapılmıştır. Bunun için coğrafik olarak birbirinden uzak üç adet AVM seçilmiş ve bir hafta içi ve bir hafta sonu, aynı haftada iki gün olarak yüz yüze uygulanmıştır. Saha araştırması sonucu 331 tüketiciden veri toplanmıştır.

Verilerin toplanmasında kullanılan anket iki bölümden oluşmuştur. Birinci bölüm demografik faktörlerden yaş, cinsiyet ve eğitim değişkenlerine ilişkin soruları içermiştir. İkinci bölümde tüketicilerin etnosentrik düzeylerini ölçmeye yönelik 17birimlik CETSCALE ölçeği yer almıştır. Orijinali 7'li Likert olan ölçek aşırı hassas olduğundan ve önceki deneyimlerden hareketle, Türk tüketicilerin bu hassasiyet farkını ortaya koymakta isteksiz olduklarından, ölçek $5^{\prime} l i$ Likert olarak düzenlenmiştir. CETSCALE ölçeğinin orjinali İngilizcedir. Ölçek Türkiye'de oldukça sık kullanılmış olduğundan, daha önceki araştırmalarda yapılan (Örs, Yılmaz, Doğan, 2016: 27) Türkçe çevirisinin kullanılması uygun görülmüştür. Araştırmada hipotez analizleri SPSS.23 kullanılarak yapılmıştır.

\section{BULGULAR VE TARTIŞMA}

Araştırmaya katılan cevaplayıcılara ilişkin tanımlayıcı istatistikler Tablo 1'de gösterilmiştir. Tablo 1'de görüldüğü üzere cevaplayıcıların \%51,1'i kadın, \%48,9'i erkek tüketicilerden oluşmaktadır. Yaş değişkeni incelendiğinde; cevaplayıııların \% 5,7'si 18 altı, \%47,1'i 18-25 yaş arası, \%33,5'i 26-44 yaş arası ve \%13,5'i 45 yaş üstüdür. Eğitim değişkenine ilişkin dağılım ise cevaplayıcıların \%4.8'i İlköğretim, \%45,9'u Lise ve \%49,3'ü üniversite mezunu şeklindedir. Eğitime ilişkin 'Okumamış' grubuna giren cevaplayıcı çıkmamıştır. 
Tablo 1: Katılımcıların Demografik Özellikleri

\begin{tabular}{||l|l|c|c|}
\cline { 3 - 4 } \multicolumn{2}{c|}{} & $\mathrm{F}$ & $\%$ \\
\hline \hline \multirow{4}{*}{ Cinsiyet } & Kadın & 169 & 51,1 \\
& Erkek & 162 & 48,9 \\
\hline \multirow{4}{*}{ Yaş } & $15-17$ & 19 & 5,7 \\
& $18-25$ & 156 & 47,1 \\
& $26-34$ & 56 & 16,9 \\
& $35-44$ & 55 & 16,6 \\
& $45-54$ & 15 & 4,5 \\
& $55-64$ & 11 & 3,3 \\
& 65 üstü & 19 & 5,7 \\
\hline \hline \multirow{3}{*}{ Eğitim } & Lilköğretim & 16 & 4,8 \\
Durumu & Lise & 152 & 45,9 \\
& Lisans & 138 & 41,7 \\
\hline Toplam & Lisansüstü & 25 & 7,6 \\
\hline \hline
\end{tabular}

Katılımcılardan Tüketici Etnosentrizmi ölçeğinde yer alan ifadelere katılma düzeyleri Tablo 2'de sunulmuştur. Buna göre CETSCALE ölçeğindeki 17 ifadeden en düşük olan ifadeler; 1,96 düzey ile "Yabancı ülke ürünlerini satın almak Türklüğe aykırıdır" ve 2,12 düzey ile "Tüm ithal ürünlere engel konmalıdır" ile en yüksek ifadeler; 3,97 düzey ile "Türk yapımı ürünler satın almak, Türkiye çalışanını korur" ve 3,44 düzey ile "Sadece Türkiye'de bulunmayan ürünler ithal edilmelidir" ifadeleridir. Ölçek birimlerine ilişkin düzeyler incelendiğinde, Türk tüketicilerin etnik kimlikten çok ülkenin ekonomik avantajını dikkate alarak tüketim davranışını sergilediği söylenebilir. CETSCALE ölçek ifadelerinin ortalamaları incelendiğinde, en düşük ortalamaya sahip olan ifadelerin ithalat engellemesine ilişkin ifadeler olduğu görülmektedir. Bu bulgu, mevcut araştırmada olduğu gibi Türk tüketicilerin etnosentrik eğilim düzeyini ölçen Çilingir'in (2014: 218) araştırma bulgusuyla benzerlik göstermekte olup, tüketicilerin kavrama rasyonel yaklaştıkları söylenebilir.

Tablo 2: Tüketici Etnosentrizmi Ölçeğine İlişkin Temel İstatistiksel Göstergeler

\begin{tabular}{|c|c|c|c|c|c|}
\hline & & Ortalama & Std. Sapma & Çarpıklık & Basıklık \\
\hline 1 & Türk halkı her zaman ithal ürünler yerine Türk yapımı ürünler satın almalıdır. & 3,2779 & 1,26542 &,- 120 &,- 963 \\
\hline 2 & Sadece Türkiye'de bulunamayan ürünler ithal edilmelidir. & 3,4441 & 1,33453 &,- 337 & $-1,121$ \\
\hline 3 & Türk yapımı ürünler satın almak, Türkiye çalışanını korur & 3,9728 & 1,09095 & $-1,087$ &, 565 \\
\hline 4 & Türk yapımı ürünler her şeyden önce gelir. & 3,1964 & 1,30062 &,- 120 & $-1,029$ \\
\hline 5 & Yabancı ülke ürünlerini satın almak Türklüğe aykırıdır. & 1,9698 & 1,26455 & 1,206 & ,286 \\
\hline 6 & Yabancı ürünler satın almak doğru değildir, çünkü Türklerin işsiz kalmasına neden olur & 2,5529 & 1,27187 &, 512 &,- 720 \\
\hline 7 & Gerçek bir Türk, her zaman Türk yapımı ürünler satın almalıdır. & 2,4350 & 1,34992 & 600 &,- 805 \\
\hline 8 & $\begin{array}{l}\text { Diğer ülkelerin bizim üzerimizden zengin olmasına müsaade etmek yerine Türkiye'de } \\
\text { üretilmiş ürünler satın almalıyız. }\end{array}$ & 3,2024 & 1,31130 &,- 184 & $-1,024$ \\
\hline 9 & Her zaman Türk ürünlerini satın almak en iyidir. & 2,9245 & 1,30164 & ,116 & $-1,037$ \\
\hline 10 & Zorunlu haller dışında, diğer ülkelerden mal satın alımı veya ticareti çok az olmalıdır. & 3,1450 & 1,34957 &,- 117 & $-1,164$ \\
\hline 11 & $\begin{array}{l}\text { Türk işletmelerine zarar verdiği ve işsizliğe neden olduğu için Türkler yabancı ürünleri satın } \\
\text { almamalıdır. }\end{array}$ & 2,7251 & 1,28862 & 233 &,- 988 \\
\hline 12 & Tüm ithal ürünlere engel konulmalıdır. & 2,1269 & 1,30810 & ,981 &,- 201 \\
\hline 13 & Uzun dönemde maliyetli de olsa, Türk ürünlerini desteklemeyi tercih ederim. & 3,1571 & 1,26471 &,- 190 &,- 961 \\
\hline 14 & Yabancıların pazarlarımıza ürünlerini sokmalarına izin verilmemelidir. & 2,2991 & 1,27848 & ,738 &,- 469 \\
\hline 15 & Türkiye'ye girişinin azaltılması için yabancı ürünler yüksek oranda vergilendirilmelidir. & 2,7251 & 1,33710 & ,230 & $-1,100$ \\
\hline 16 & Sadece kendi ülkemizde bulamadığımız ürünleri yabancı ülkelerden satın almalıyız. & 3,2326 & 1,33154 &,- 294 & $-1,096$ \\
\hline 17 & $\begin{array}{l}\text { Diğer ülkelerde üretilen ürünleri satın alan Türk tüketicileri, vatandaşları olan Türk halkının } \\
\text { işsizliğine neden olmakla sorumludurlar. }\end{array}$ & 2,5136 & 1,32424 & ,483 &,- 916 \\
\hline
\end{tabular}

Türk tüketicilerinin etnosentrik eğilim düzeylerini ölçmek için Cetscale ölçeği ile yapılan ölçümde, ölçekteki tüm değişkenlerin çarpıklık ve basıklık değerleri -2 ile +2 aralığında gerçekleşmiştir. Sosyal bilimler alanında yapılan çalışmalarda bir ölçeğin değişkenlerinin normal dağılım göstermesi için ölçeğin çarpıklık ve basıklık değerlerinin -2 ile +2 aralığında gerçekleşme zorunluğu (Garson, 2012: 18) kabulüne istinaden, araştırmada kullanılan ölçeğin değişkenlerinin normal dağıldığı söylenebilir.

Araştırmanın ölçümünün güvenilirliğini test etmeden önce, faktör sayısı bir olacak şekilde kısıtlama yapılarak Keşifsel Faktör Analizi gerçekleştirilmiş, elde edilen faktör yükleri Tablo 3'te sunulmuştur. 
Tablo 3. Tüketici Etnosentrizmi Ölçeği Tek Boyutluluk Analizi

\begin{tabular}{|c|c|}
\hline ifadeler & Faktör1 \\
\hline ifade 17 &, 821 \\
\hline ifade 9 &, 814 \\
\hline ifade 7 &, 801 \\
\hline ifade 8 &, 800 \\
\hline ifade 11 &, 796 \\
\hline ifade 10 &, 746 \\
\hline ifade 6 &, 743 \\
\hline ifade 15 &, 714 \\
\hline ifade 14 &, 707 \\
\hline ifade 13 &, 698 \\
\hline ifade 16 &, 692 \\
\hline ifade 4 &, 686 \\
\hline ifade 5 &, 685 \\
\hline ifade 12 &, 674 \\
\hline ifade 1 &, 647 \\
\hline ifade 2 &, 592 \\
\hline ifade 3 &, 498 \\
\hline
\end{tabular}

KMO Measure of Sampling Adequacy $=, 941$ Bartlett's Test of Sphericity Approx. Chi-Square $=3665,544$ sign= 0,000

Tablo 3'te görüldüğü üzere, ölçekteki 17 ifade ile yapılan ölçüm için hesaplanan Cronbach alfa katsayısı 0,93 olarak gerçekleşmiştir. Ölçeğin Cronbach alfa değeri 0,70'in üzerinde ( Nunnally, 1970: 245) olduğundan ve ölçek ifadelerin düzeltilmiş madde toplam puan korelasyon değerlerinin de 0,35'in üzerinde (Bearden, Hadesty, Rose, 2001) bulunduğundan ölçeğin içsel tutarlılığının yüksek olduğu söylenebilir. Ölçeğin değişkenlerin faktör yükleri incelendiğinde, tüm değiş̧enlerin 0,45'in üzerinde değer aldıkları görülmektedir.

"Tüketicilerin etnosentrizm düzeyleri, cinsiyete göre farklılık gösterir" şeklinde ifade edilen $\mathrm{H}_{1}$, t-test ile test edilmiştir. Analiz sonuçları Tablo 4'te gösterilmiş olup, hipotez 0,05 anlamlılık düzeyinde ret edilmiş olup, 0,10 anlamlılık düzeyinde kabul edilmiştir. Buna göre erkeklerin etnosentrik tüketim düzeyinin kadınların düzeyinden daha yüksek olduğu söylenebilir. Bu bulgu Kemmelmeler'ın (2010) araştırma bulgusu ile benzerlik, Armağan ve Gürsoy'un (2011) araştırma bulguları ile farklılık göstermektedir.

Tablo 4: Tüketici Etnosentrizm Düzeyleri Ile Cinsiyet Faktörlerine ilişsin t-Testi Sonuçları

\begin{tabular}{|c|c|c|c|c|c|}
\hline & Cinsiyet & $\mathrm{N}$ & Ortalama & t-değeri & Anlamlılık \\
\hline \multirow{2}{*}{$\begin{array}{l}\text { Etnosentrizm } \\
\text { Düzeyi }\end{array}$} & Erkek & 162 & 2,9720 & \multirow{2}{*}{1,848} & \multirow{2}{*}{,066 } \\
\hline & Kadın & 169 & 2,7849 & & \\
\hline
\end{tabular}

"Tüketicilerin etnosentrizm düzeyleri, yaşlarına göre farklılık gösterir" şeklinde ifade edilen $\mathrm{H}_{2}$ 'nin sonuçları Tablo 5 'te gösterilmiştir. Hipotez 0,05 anlamlılık düzeyinde varyans analizi ile test edilmiştir. Tablodan görüldügü üzere, tüketici etnosentrik eğilim düzeyleri yaş grupları arasında istatistiksel olarak anlamlı bulunmamıştır. Bu bulgu Shankarmahesh'ın (2006) ve Bawa'nın (2004) elde ettikleri bulgulardan farklıdır. Bu farkın temel nedeninin araştırmanın yapıldığı ülkelerin birbirlerinden oldukça farklı olan kültürlerinden kaynaklandığı söylenebilir.

Tablo 5: Tüketici Etnosentrizm Düzeyleri İle Yaş Faktörlerine ilişskin Varyans Analizi Sonuçları

\begin{tabular}{|l|c|c|c|c|}
\hline & $\mathrm{N}$ & Ortalama & F-değeri & Anlamlılık \\
\hline $15-18$ & 19 & 2,9659 & & \\
\cline { 1 - 3 } $19-25$ & 156 & 2,9683 & & \\
\cline { 1 - 3 } $26-34$ & 56 & 2,8183 & \multirow{2}{*}{1,164} & \multirow{2}{*}{, 325} \\
\cline { 1 - 3 } $35-44$ & 55 & 2,6952 & & \\
\cline { 1 - 3 } $45-54$ & 15 & 2,6902 & & \\
\cline { 1 - 3 } $55-64$ & 11 & 2,5401 & & \\
\hline 65 üstü & 19 & 3,0712 & & \\
\cline { 1 - 3 } Toplam & 331 & 2,8765 & & \\
\hline
\end{tabular}

"Tüketicilerin etnosentrizm düzeyleri eğitim durumlarına göre farklııı gösterir" şeklinde ifade edilen $\mathrm{H}_{3}$, varyans analizi ile test edilmiş ve sonuçlar Tablo 6'da gösterilmiştir. Tablodaki sonuçlara bağlı olarak $\mathrm{H}_{3}$ hipotezi kabul edilmiştir. Buna göre; tüketicilerin etnosentrik düzeyleri, eğitim durumlarına göre farklılık göstermektedir. Bu bulgu Sharma ve arkadaşlarının (1995) yaptığı araştırma bulgusu ile benzerlik göstermektedir. Hipotez testi sonucunda elde edilen eğitim düzeyi farklılığının 
hangi gruplar arasında olduğunu görmek için yapılan Post-Hoc testi sonuçları Tablo 7'de gösterilmiştir. Grupların varyansları homojen olmadığı için (Levene testi $6,428 p=, 000$ ), Tamhane ve Dunnett T3 testleri gerçekleştirilmiştir. Yapılan analizin sonuçlarına göre gruplar arası farklılı̆ın, ilköğretim mezunlarının etnosentrik eğilimlerinin lise, üniversite ve lisansüstü mezunlarına göre daha yüksek olmasından kaynaklandığı tespit edilmiştir. Buna göre Illköğretim mezunlarının lise, üniversite ve yüksek lisans mezunlarına kıyasla daha etnosentrik oldukları bulgusu elde edilmiştir. Bununla birlikte Lisansüstü mezunlarının etnosentrik eğilimlerinin diğerlerine kıyasla daha düşük olduğu da görülmektedir. Ortalamalarla birlikte ele alındığında bu bulgular ışığında eğitim düzeyi arttıkça etnosentrik eğilimin azaldığını söylenebilir.

Tablo 6: Tüketici Etnosentrizm Düzeyleri İle Eğitim Faktörlerine ilişsin Varyans Analizi Sonuçları

\begin{tabular}{|l|r|r|r|r|}
\hline & \multicolumn{1}{|c|}{ N } & Ortalama & \multirow{2}{*}{ F-değeri } & Anlamlılık \\
\cline { 1 - 3 } \cline { 1 - 2 } Ilköğretim & 16 & 3,7426 & & \\
\cline { 1 - 3 } Lise & 152 & 2,9303 & & \\
\cline { 1 - 3 } Üniversite & 138 & 2,8291 & \multirow{2}{*}{9,386} & \multirow{2}{*}{000} \\
\cline { 1 - 3 } Lisansüstü & 25 & 2,2565 & & \\
\cline { 1 - 3 } Toplam & 331 & 2,8765 & & \\
\hline
\end{tabular}

Tablo 7: Etnosentrizm Düzeyleri Arasındaki Farkın Kaynağını Belirlemek Üzere Uygulanan Post-Hoc Testlerine iliş̧kin Sonuçlar- Eğitim Faktörü

\begin{tabular}{|c|c|c|c|c|c|c|}
\hline & & & & & \multicolumn{2}{|c|}{ \%95 Güven Aralığı } \\
\hline & $\begin{array}{c}\text { Eğitim } \\
\text { Düzeyi (I) }\end{array}$ & $\begin{array}{c}\text { Eğitim } \\
\text { Düzeyi (J) }\end{array}$ & $\begin{array}{l}\text { Ortalama } \\
\text { Farkı (I-J) }\end{array}$ & Anlamlılık & Alt Sınır & Üst Sınır \\
\hline \multirow[t]{12}{*}{ Tamhane } & \multirow[t]{3}{*}{ ilköğretim } & Lise &, $81231^{*}$ & ,000 &, 4425 & 1,1821 \\
\hline & & Üniversite &, $91358^{*}$ &, 000 & ,5435 & 1,2837 \\
\hline & & Lisansütü & $1,48618^{*}$ & ,000 & 1,0519 & 1,9205 \\
\hline & \multirow[t]{3}{*}{ Lise } & İlköğretim &,$- 81231^{*}$ & ,000 & $-1,1821$ &,- 4425 \\
\hline & & Üniversite & ,10127 & ,927 &,- 1879 & ,3904 \\
\hline & & Lisansüstü &, $67387^{*}$ & ,000 & ,2975 & 1,0502 \\
\hline & \multirow[t]{3}{*}{ Üniversite } & İlköğretim &,$- 91358^{*}$ &, 000 & $-1,2837$ &,- 5435 \\
\hline & & Lise &,- 10127 & ,927 &,- 3904 & 1879 \\
\hline & & Lisansüstü &, $57260^{*}$ &, 001 & ,1960 &, 9492 \\
\hline & \multirow[t]{3}{*}{ Lisansüstü } & İlköğretim & $-1,48618^{*}$ &, 000 & $-1,9205$ & $-1,0519$ \\
\hline & & Lise &,$- 67387^{*}$ &, 000 & $-1,0502$ &,- 2975 \\
\hline & & Üniversite &,$- 57260^{*}$ &, 001 &,- 9492 &,- 1960 \\
\hline \multirow[t]{12}{*}{ Dunnett T3 } & \multirow[t]{3}{*}{ İlköğretim } & Lise &, $81231^{*}$ & ,000 & ,4437 & 1,1809 \\
\hline & & Üniversite & ,91358 &, 000 &, 5447 & 1,2824 \\
\hline & & Lisansüstü & $1,48618^{*}$ &, 000 & 1,0531 & 1,9192 \\
\hline & \multirow[t]{3}{*}{ Lise } & Lise &,$- 81231^{*}$ & ,000 & $-1,1809$ &,- 4437 \\
\hline & & Üniversite & ,10127 & ,926 &,- 1878 & ,3903 \\
\hline & & Lisansüstü &, $67387^{*}$ & ,000 & ,2983 & 1,0494 \\
\hline & \multirow[t]{3}{*}{ Üniversite } & İlköğretim &,$- 91358^{*}$ &, 000 & $-1,2824$ &,- 5447 \\
\hline & & Lise &,- 10127 & ,926 &,- 3903 & ,1878 \\
\hline & & Lisansüstü &, $57260^{*}$ & ,001 & ,1968 & ,9484 \\
\hline & \multirow[t]{3}{*}{ Lisansüstü } & İlköğretim & $-1,48618^{*}$ &, 000 & $-1,9192$ & $-1,0531$ \\
\hline & & Lise &,$- 67387^{*}$ & ,000 & $-1,0494$ &,- 2983 \\
\hline & & Üniversite &,$- 57260^{*}$ & ,001 &,- 9484 &,- 1968 \\
\hline
\end{tabular}

Araştırma amacı dikkate alınarak, Türk tüketicilerin etnosentrik eğilim düzeyleri 17-birimlik 5'li Likert ölçeği ile ölçülmüş ve ortalama bir skor elde edilmiştir. Buna göre katılımcıların etnosentrik eğilimleri Tablo 8'de görüldüğü üzere, 'orta' düzeyde gerçekleşmiştir $(\bar{X}=2,8765$ ve CETSCORE= 48,90). Bu sonuç, Türkiye'de gerçekleştirilen bazı araştırma bulgularından (Yapraklı, Keser, 2013; Çilingir, 2014) farklılık göstermekle beraber, daha büyük bir oranla ise bazı araştırma bulguları (Turgut, 2010; Asil, Kaya, 2013; Uyar, Dursun, 2015; Arı, Madran, 2011; Armağan, Gürsoy, 2011; Akın, Çiçek, Gürbüz \& İnal, 2009; İşler, 2013; vd. ) ile benzerlik göstermektedir. 
Tablo 8: Türk Tüketicilerin Etosentrik Eğilim Düzeyleri

\begin{tabular}{|l|r|r|}
\hline \multicolumn{1}{|c|}{ Skor Aralığı } & Sıklık (f) & Yüzde (\%) \\
\hline 17-41 (Düşük Etnosentrizm) & 120 & 36,3 \\
\hline 42-55 (Orta Etnosentrizm) & 99 & 29,9 \\
\hline 56-85 (Yüksek Etnosentrizm) & 112 & 33,8 \\
\hline Toplam & 331 & 100,0 \\
\hline
\end{tabular}

Türk tüketicileri üzerinde önceki araştırmalardan aynı ölçeğin 5'li Likert ile yapılan ölçümlerinden elde edilen etnosentrik eğilim skorları (Çilingir, 2014: 223) Tablo 9'da gösterilmiştir. Buna göre genel itibariyle Türk tüketicilerinin etnosentrik eğilim düzeyinin 'orta' düzeyde olduğu söylenebilir. Bunun yanı sıra pazarlama yazınında önceki araştırmalar ile Amerika, Polonya, Rusya, Çek Cumhuriyeti, Estonya, Macaristan, Yeni Zelanda ve Hindistan ülkelerinin de tüketici etnosentrik eğilim düzeylerinin 'orta' düzeyde ( Çilingir, 2014: 223) gerçekleştiği ortaya konmuştur.

Tablo 9: Türk Tüketicilerinin Etnosentrik Eğilim Ortalama Puanı ve Düzeyleri

\begin{tabular}{|l|c|c|}
\hline Araştırma & Cetscale Skoru & Cetscale Düzeyi \\
\hline Aysuna (2006) & 50,8 & Orta \\
\hline Arı (2007) & 45,9 & Orta \\
\hline Çakır (2008) & 51,9 & Orta \\
\hline Akın ve arkadaşları (2009) & 54,5 & Orta \\
\hline Turgut (2010) & 48,2 & Orta \\
\hline Armağan ve Gürsoy (2011) & 51,4 & Orta \\
\hline Asil ve Kaya (2013) & 46,5 & Orta \\
\hline Mevcut Araştırma (2017) & $\mathbf{4 8 , 9}$ & Orta \\
\hline
\end{tabular}

\section{SONUÇ}

Mevcut araştırma ile küreselleşmenin kültürel etkilerine ilişkin sosyoloji yazınında yer alan üç tez, tüketici etnosentrizmi aracılı̆ııla sınanmış ve cinsiyet, yaş, eğitim faktörlerine göre tüketicilerin etnosentrik eğilimleri incelenmiştir. Araştırmada kullanılan 17-birimlik CETSCALE ölçeği ile yapılan ölçüm güvenilir bulunmuştur. Araştırma 331 tüketici üzerinde, yüz yüze anket şeklinde yapılmıştır. Araştırma sonuçları aşağıda özetlenmiştir:

Tüketici etnosentrizm düzeyi yaş faktörlerine göre farklılık göstermemekte, ancak cinsiyet ve eğitim faktörüne göre farklılık göstermektedir. Araştırma ile erkeklerin etnosentrik tüketim eğiliminin kadınlara kıyasla daha yüksek olduğu bulunmuştur. Araştırmadaki bir diğer demografik faktör olan eğitim düzeyine göre etnosentrik tüketim eğilim düzeyinde anlamlı farklılık çıkmıştır. Bu farkın İlköğretim ile Lise ve İlköğretim ile Üniversite grupları arasında olduğu elde edilmiştir.

Araştırma amacına bağlı olarak hesaplanan Türk tüketicilerin etnosentrik eğilim düzeyi orta düzeyde gerçekleşmiştir. Literatür taramasında Türk tüketicileri üzerinde aynı ölçek ile yapılan ölçümlerde etnosentrik eğilim düzeyinin ağırlıklı olarak orta düzeyde gerçekleştiğinden, Türk tüketicilerinin genel olarak etnosentrik eğilim düzeyinin 'orta' düzeyde olduğu söylenebilir. Araştırma bulgusu ve önceki araştırmalar dikkate alınarak, tüketicilerin etnosentrik eğilim düzeylerinin ağırlıklı olarak 'orta' düzeyde gerçekleşmesine dayanarak, küreselleşmenin kültürel etkilerine ilişkin üç olası tez olan homojenleşme, kutuplaşma ve hibritleşme tezlerinden hibritleşme tezini desteklemiştir.

Küreselleşme gerek sosyal, gerek ekonomik ve gerekse kültürel etki gücüne sahip olan, günümüz ve gelecekte yaşamın birçok alanını yapılandırma özelliğinden dolayı etkisi gün geçtikçe artan bir konu olma özelliği taşımaktadır. Bu gerçekle küreselleşme ve yarattığı sonuçlar üzerinde yapılacak araştırmalar, ekonomilerdeki aktörlerin geleceğe ilişkin yol haritalarını oluşturmalarına temel olacağı aşikardır. Bu anlamda araştırma sonuçlarının gerek pazarlama ve tüketici davranışları, gerekse sosyoloji ana bilim dallarına önemli bulgular verdiği söylenebilir. Araştırma bulgusu ile elde edilen küreselleşmenin kültüre olan etkisinin hibrit özellik göstermesi, pazarlama yönetiminin dış pazarlara girerken hem yerel kültür ögeleri ve kabullerini dikkate alan hem de çağın gelişmesi/dönüşmesi ile olagelen küresel kültürü en üst düzeyde örtüştürecek pazarlama karması oluşturmaları gereğini ortaya koymuştur. 


\section{KAYNAKLAR}

Akın, M., Çiçek, R., Gürbüz, E. \& İnal, E.M. 2009, "Tüketici etnosentrizmi ve davranış niyetleri arasındaki farklılığın belirlenmesinde Cetscale ölçeği", Ege Akademik Bakış Dergisi, 9 (2), pp 489-512.

Altıntaş, M. H. \& Tokol, T. 2007, "Cultural openness and consumer ethnocentrism: An empirical analysis of Turkish consumers", Marketing Intelligence and Planning, 25(4), pp.308-325.

Arı, E.S. \& Madran, C. 2011, "Satın alma kararlarında tüketici etnosentrizmi ve menşe ülke etkisinin rolü", Marmara Üniversitesi Sosyal Bilimler Enstitüsü Öneri Dergisi, 9(35), pp.15-33.

Armağan, E. A. \& Gürsoy, Ö. 2011, "Satın alma kararlarında tüketici etnosentrizmi ve menşe ülke etkisinin cetscale ölçeği ile değerlendirilmesi", Organizasyon ve Yönetim Bilimleri Dergisi, Cilt 3, Sayı 2, pp. 67-77

Asil, H. \& Kaya, I. 2013, "Türk tüketicilerin etnosentrik eğilimlerinin belirlenmesi üzerine bir araştırma", İstanbul Üniversitesi İşletme Fakültesi Dergisi, 42(1), pp. 113-132.

Balabanis, G. \& Diamantopoulis, A. 2004, “Domestic country bias, contry-of-origin effects, and consumer ethnocentrism: A multidimensional unfolding approach", Academy of Marketing Science Journal, 32(1), pp. 80-95.

Bawa, A. 2004, "Consumer ethnocentrism: CETSCALE validation and measurement of extent", VIKALPA, 29(3), pp.43-55 iç. Hamelin, N., Ellouzi, M. Ve Canterbuy, A. (2011). Consumer ethnocentrism and country-of-origin effects in the Moraccan market, Journal of Global Marketing, 24, 228-244. DOI: 10.1080/08911762.2011.592459

Bearden, W.O., Hardesty, D.M. \& Rose, R.L.. 2001, "Consumer self-confidence: Refinements in conceptualization and measurement", Journal of Consumer Research, 28(1) (June), pp.121-134.

Cateora, P. 2000, International marketing, Irwin iç. Saffu, K. Ve Walker, J.H. (2005). An assessment of the consumer ethnocentric scale (CETSCALE) in an advanced and transitional country: The case of Canada and Russia, International Journal of Management, 22(4), 556-571.

Çilingir, Z. 2014, "Tüketici etnik kökenciliği eğilimi ölçeği (CETSCALE): İstanbul ili tüketicileri üzerine bir pilot araştırma", International Journal of Economic and Administrative Studies, 7 (13), pp.209-232.

Garson, D.G. 2012. Testing statistical assumptions. 2012 Ed. Statistical Publishing Associates:USA iç. Çilingir, Z. (2014). Tüketici etnik kökenciliği eğilimi ölçeği (CETSCALE): İstanbul ili tüketicileri üzerine bir pilot araştırma. International Journal of Economic and Administrative Studies, 7 (13), pp.209-232.

Giddens, A. 1998, Modernliğin sonuçları, Ayrıntı Yayınları, İstanbul.

Hannerz, U. 1998, Çevre kültür senaryoları. Küreselleşme ve Dünya Sistemi, Çev. G. Seçkin ve H.Yolsal, Bilim ve Sanat Yayınları, Ankara.

Harvey, U. 1992, The condition of postmodernity. Blackwell, Oxford. İç. Holton, R. (2013), Küreselleşmenin Kültürel Sonuçları, Sosyoloji Konferansları, 47(1): 59-75.

Holton, R. 2013, “Küreselleşmenin kültürel sonuçları", Sosyoloji Konferansları, 47(1), pp. 59-75.

İşler, D. B. 2013, "Tüketici entrosentrizmi ve menşe ülke etkisi ekseninde satın alma kararlarındaki rolü: CETSCALE ölçeği ile bir uygulama", Abant Izzet Baysal Üniversitesi Sosyal Bilimler Enstitüsü Dergisi, 26(26), pp. 93-122.

Kaynak, E. \& Kara, A. 2000, "Consumer perceptions of foreign products: An analysis of product-country images and ethnocentrism", European Journal of Marketing, 36(7/8), pp.928-949.

Kemmelmeir, M. 2010, "Gender moderates the impacts of need for structure on social beliefs: Implications for ethnocentrism and authoritarianism", International Journal of Psychology, 45(3), pp.202-211.

Keyman, F. 1998, “Globalleşme ve öteki sorunu: Postmodernizm, feminizml, oryantalizm”, Küreselleşme, Sivil Toplum ve İslam, Vadi Yayınları, Ankara. İç. İçli, G. (2001), “Küreselleşme ve Kültür”, C.Ü. Sosyal Bilimler Dergisi, Aralık 25(2), PP.163-172.

Klein, J.G.,Ettenson, R. \& Morris, M.D. 1998, "The animosity model of foreign product purchase: An empirical test in the People's Republic of China", Journal of Marketing, 62(1), pp. 89-100.

McNeill, W. 1986, Polyethnicity and national unity in world history. University of Chicago Press. İç.Holton, R. (2013), Küreselleşmenin Kültürel Sonuçları, Sosyoloji Konferansları, 47(1): 59-75.

Netemeyer, R.G.,Durvasula, S. \& Lichtenstein, D.R. 1991, "A cross-national assessment of the reliability and validity of the CETSCALE", Journal of Marketing Research, 28(8), pp. 320-327.

Nunnally, J. C. 1978, Psychometric Theory. 2nd Ed. New York. McGraw Hill.

Örs, H., Yılmaz, V. \& Doğan, M. 2016, "Effect of consumer ethnocentrism on perceived service quality and examination of this contex by cultural relativity and demographic factors: An empirical Study", Journal of Management, Marketing and Logistics, pp. 14-27.

Robertson, R. 1998, Toplum kuramı, kültürel görecelik ve küresellik sorunu. Küreselleşme ve Dünya Sistemi, Çev. G. Seçkin ve H.Yolsal, Bilim ve Sanat Yayınları, Ankara.

Shankarmahesh, M. N. 2006, "Consumer ethnosentrism: An integrative review of its antecedents and consequences", International Marketing Review, 23(2), pp. 146-172. 
Sharma, S. \& Shimp, T.A. \& Shin, J. 1995, "Consumer ethnocentrism: A test of anteceedents and moderatorts", Journal of the Academy of Marketing Science, 23(1), pp.26-37.

Shimp, T.A. \& Sharma, S. 1987, "Consumer ethnocentrism: Consruction and validation of the CETSCALE", Journal of Marketing Research, 24(8), pp. 280-289.

Turgut, B. A. 2010, "Tüketici etnosentrizminin satınalma davranışlarına etkisi: Hizmet sektöründe bir uygulama". Yayınlanmamış Yüksek Lisans Tezi, Balıkesir Üniversitesi, Sosyal Bilimler Enstitüsü.

Uyar, K. \& Dursun, Y. 2015, “Farklı ürün kategorilerinde yabancı markalama ve tüketici Etnosentrizmi”, Atatürk Üniversitesi Sosyal Bilimler Enstitüsü Dergisi, 19 (2), pp.363-382

Wang, C. I. \& Chen, Z.Y. 2004, "Consumer ethnocentrism and willingness to buy domestic products in a developing country setting testing moderating effects", Journal of Consumer Marketing, 21(6), 391-400.

Yapraklı, T. Ş. \& Keser, E. 2013, "Tüketici etnosentrizmi: Beyaz eşya ve içecek sektörlerinde karşılaştırmalı bir saha araştırması", Sosyal Ekonomik Araştırmalar Dergisi, (25), pp. 385-420. 